\title{
Minerals on the edge: sediment-hosted base metal endowment above steps in lithospheric thickness
}

\author{
K. Czarnota1, M. J. Hoggard ${ }^{2,3}$, F. D. Richards ${ }^{4}$, M. Teh ${ }^{1}$, D. L. Huston ${ }^{1}$, A. L. Jaques ${ }^{5}$ and \\ S. Ghelichkhan ${ }^{5}$ \\ ${ }^{1}$ Geoscience Australia, ${ }^{2}$ Harvard University, USA, ${ }^{3}$ Columbia University, USA, ${ }^{4}$ Imperial College London, UK, ${ }^{5}$ Australian \\ National University
}

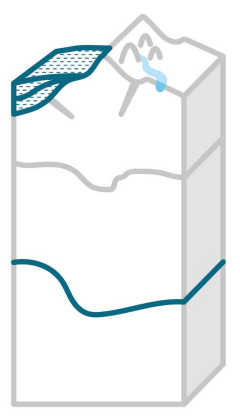

To meet the rising global demand for base metals - driven primarily by the transition to cleaner-energy sources declining rates of discovery of new deposits need to be countered by advances in exploration undercover. Here, we report that $85 \%$ of the world's sediment-hosted base metals, including all giant deposits ( $>10 \mathrm{Mt}$ of metal), occur within $200 \mathrm{~km}$ of the edge of thick lithosphere, irrespective of the age of mineralisation. This implies long-term craton edge stability, forcing a reconsideration of basin dynamics and the sediment-hosted mineral system. We find that the thermochemical structure of thick lithosphere results in increased basin subsidence rates during rifting, coupled with low geothermal gradients, which ensure favourable metal solubility and precipitation. Sediments in such basins generally contain all necessary lithofacies of the mineral system. These considerations allow establishment of the first-ever national prospectus for sediment-hosted base metal discovery. Conservative estimates place the undiscovered resource of sediment-hosted base metals in Australia to be $\sim 50-200$ Mt of metal. Importantly, this work suggests that $\sim 15 \%$ of Australia is prospective for giant sediment-hosted deposits; we suggest that exploration efforts should be focused in this area.

The global transition to a cleaner-energy economy is driving demand for base metals $(\mathrm{Cu}, \mathrm{Pb}, \mathrm{Zn}$ and $\mathrm{Ni})$, but significant shortfalls are forecast over the coming decades as discovery rates for new deposits decline (Ali et al., 2017; Schodde, 2017). Australia is not immune, despite hosting many highquality sediment-hosted $\mathrm{Cu}, \mathrm{Pb}$ and $\mathrm{Zn}$ deposits with companion critical minerals (Mudd et al., 2019). A consensus is emerging that the mineral exploration frontier now lies beneath post-mineralisation cover.

The undercover search space is vast ( $80 \%$ of Australia) and drastically undersampled. Undercover exploration needs to focus on provinces with the greatest potential for new giant discoveries. The most common approach is to develop a conceptual genetic model of a deposit type largely based on ore deposit studies, and then interrogate spatial databases for key proxies (Hronsky and Groves, 2008). The genesis of sediment-hosted deposits requires oxidised, moderatetemperature $\left(80-250^{\circ} \mathrm{C}\right)$ and moderate- to high-salinity fluids (10-30 wt. \% NaCl) that are sourced from evaporites. These brines scavenge metals as they flow through voluminous oxidised terrestrial sediments intercalated with magmatic rocks, before they are focused along faults into oxidationreduction depositional interfaces such as black shales (Figure 1; Hitzman et al., 2010; Leach et al., 2010). The necessary lithologies for this mineral system can be locally identified in surface geological maps, but have so far been difficult to identify undercover, as systematic subsurface geological maps are in their infancy (Stewart et al., 2020). An alternative approach is to identify fertile basins at the regional scale by screening stacked geological provinces for the presence or absence of these key lithologies using the Australian Stratigraphic Units Database (ASUD; Stewart et al., 2013). These mineral system ingredients are common in many failed rifts and passive margins, so this approach only reduces the search space in Australia to $\sim 60 \%$.

Further reductions in exploration area at the national scale require extensive, homogenous datasets that have mineral system implications (Hronsky and Groves, 2008).

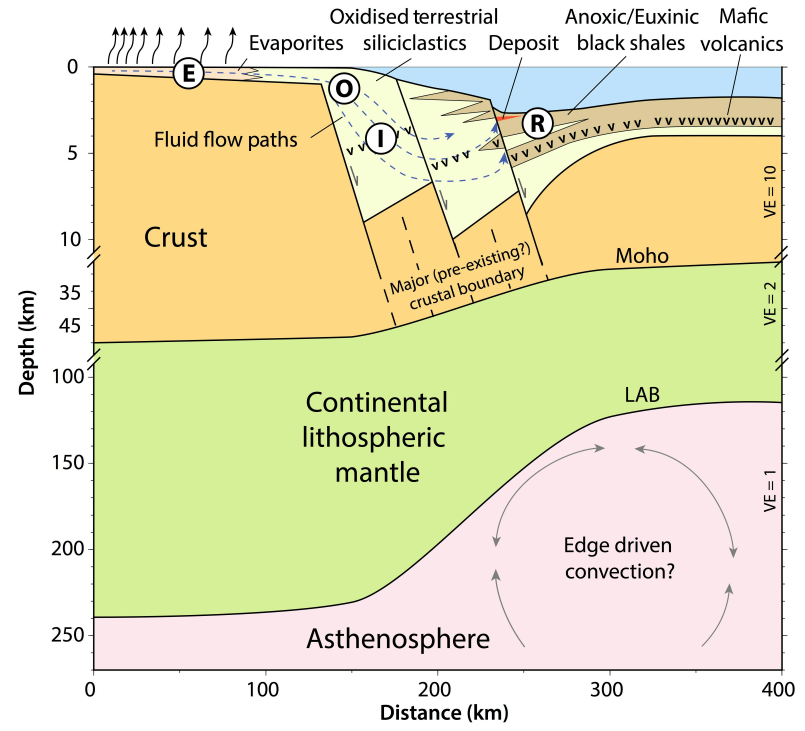

Figure 1 Schematic rift-related lithospheric architecture and four key sediment-hosted base metal mineral system components: (E)vaporitic source of basinal brines that scavenge metals from (O)xidised terrestrial sediments and (I)gneous mafic rocks on route to $(R)$ eduction interfaces, such as black shales, where metals are deposited. Notice variable vertical exaggeration (VE) and prominence of the lithosphere-asthenosphere boundary $(L A B)$ at 1:1 scale. Schematic based on deep reflection seismic profiles across the North Australian Zinc Belt and modelling by Manning and Emsbo (2018). Lithological proxies for the four components are E: Evaporite, Halite, Gypsum, Barite, Scapolite, Cauliflower chert, Sabkha, Stromatolite, Hopper crystals, Oncolite and Anhydrite; O: Dolostone, Dolomite, Dolo, Limestone and Arkose; I: Basalt, Mafic, Tholeiitic, Dolerite, Gabbro, Greenstone, Basic; R: <2 Ga, Black Shale, Carbonaceous.

Among others, seismic tomography techniques are ideal for providing this coverage, as seismic waves sample regions located between sparse seismometer stations (Gorbatov et al., 2020). For almost a decade, seismic tomography has been used to map first-order lithospheric mantle controls on magmatic ore deposits (Griffin et al., 2013). In contrast, deep 


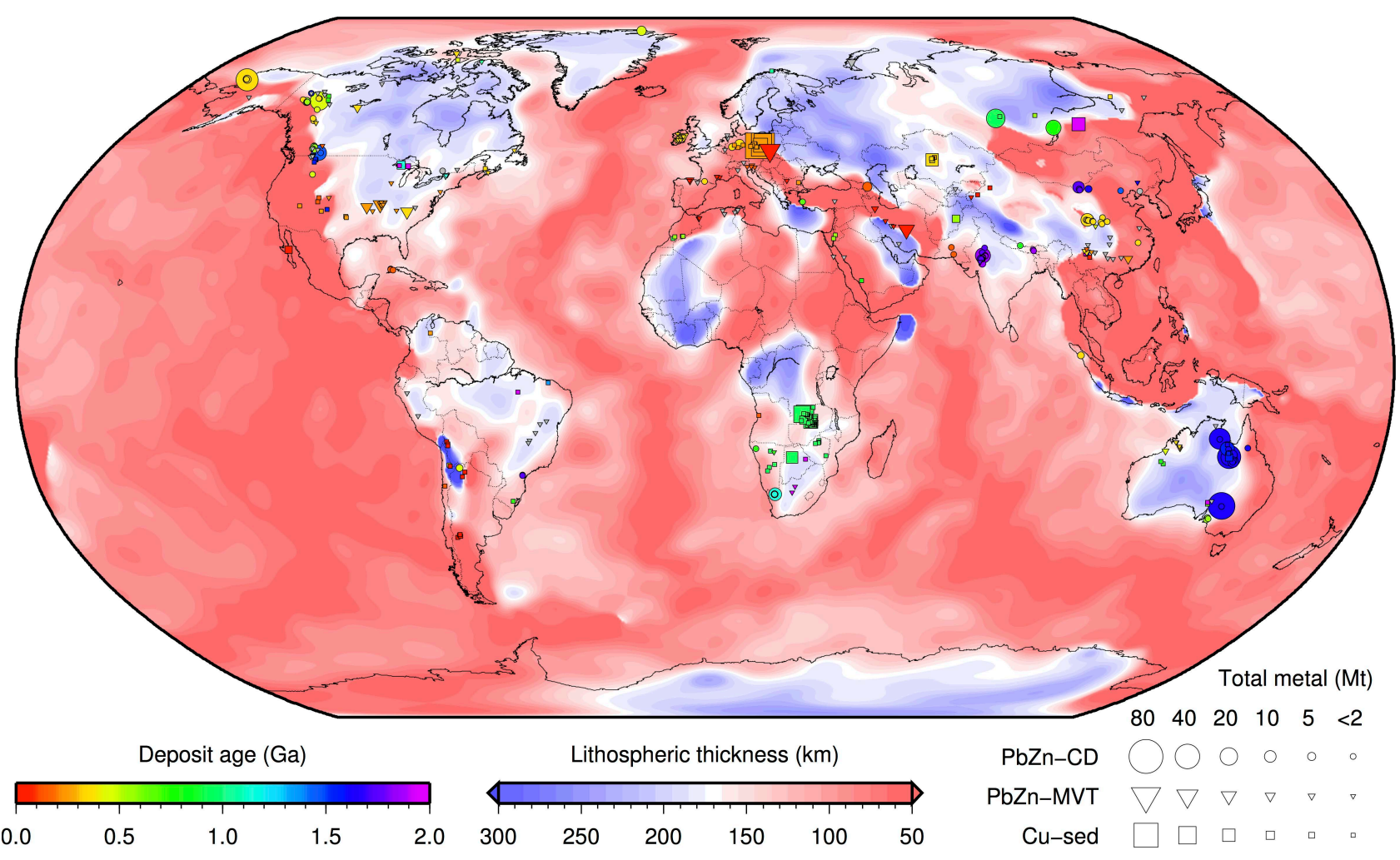

Figure 2: Global distribution of sediment-hosted base metal deposits as a function of lithospheric thickness. LAB derived from SL2013sv tomography model using a calibrated anelasticity parameterisation (Schaeffer and Lebedev, 2013; Yamauchi and Takei, 2016; Richards et al., in press). Symbols show deposit locations, coloured by deposit age ( $\mathrm{Ga}=$ billion years) and proportional in size to total contained mass of metal (Mt = megatonnes); unknown deposit size is given a 2 Mt symbol; unknown deposit age is plotted in grey; circles are clastic dominated lead-zinc (PbZn-CD); triangles are Mississippi Valley-type leadzinc (PbZn-MVT); squares are sedimentary copper (Cu-sed).

controls on sediment-hosted mineral systems have been largely overlooked, even though the influence of lithospheric structure on basin genesis is well established (McKenzie, 1978). As part of the Exploring for the Future program, Hoggard et al. (in press) discovered that all giant sedimenthosted mineral deposits (>10 Mt metal) are located above steps in the most fundamental upper mantle structure - the lithosphere-asthenosphere boundary (LAB). Here, we review this finding and the implications for mineral potential in undercover regions of Australia.

\section{Lithospheric control on mineralisation}

Given the sporadic distribution of giant mineral deposits, robust linking of geological features to deposit locations is best achieved through a global study. To this end, we compiled a global inventory of six major base metal deposit types from published sources. Three are associated with magmatic process, and three are sediment hosted: sedimentary copper (Cu-sed), clastic-dominated lead-zinc (PbZn-CD, or sedimentary exhalative) and Mississippi Valley-type lead-zinc (PbZn-MVT). Next, we used a method developed by Priestley and McKenzie (2013) of mapping the thermal LAB from seismic tomography, refined by Richards et al. (in press). This method takes into consideration recent laboratory experiments on the effect of anelasticity on shearwave velocities (Yamauchi and Takei, 2016). We calculated a global LAB using the SL2013sv tomography model, calibrated to the latest thermal structure of cooling oceanic lithosphere (Schaeffer and Lebedev, 2013; Richards et al., 2018). We also calculated a higher-resolution Australian LAB using the FR12 tomography model (Fishwick and Rawlinson, 2012), calibrated using nine local paleogeotherms derived from thermobarometry of mantle xenoliths and xenocrysts.
The global $L A B$ reveals a striking relationship between major sediment-hosted mineral deposits and the edge of thick lithosphere, outlined by the $170 \mathrm{~km}$ depth contour (Figure 2). This relationship is even clearer in the higher-resolution model of Australia, with iron-oxide-copper-gold (IOCG) deposits also lying along the same trend, including Olympic Dam (Figure 3a). Unfortunately, ongoing uncertainty in classification schemes of IOCG deposits has hindered our attempt to perform a global assessment of these systems.

To quantify the relationship, we calculated the distance between each sediment-hosted deposit and the $170 \mathrm{~km} \mathrm{LAB}$ depth contour, and plotted the cumulative distribution function, weighting by the mass of metal within each deposit (Figure $3 \mathrm{~b}$ ). Globally, we find that $~ 90 \%$ of Cu-sed, $~ 90 \%$ of PbZn-CD and $\sim 70 \%$ of PbZn-MVT resources are located within $200 \mathrm{~km}$ of the $170 \mathrm{~km} \mathrm{LAB}$ depth contour (Figure 3b). This corridor corresponds to only one-third of continental surface area and encapsulates all giant sediment-hosted deposits. Since the width of this zone is similar to the $\sim 280 \mathrm{~km}$ horizontal node spacing in SL2013sv, tighter constraints are only possible with higher-resolution tomography models. Indeed, all giant sediment-hosted and IOCG deposits in our higher-resolution model of Australia are located within $100 \mathrm{~km}$ of the $170 \mathrm{~km}$ LAB depth contour, illustrating the great benefit of increasing the passive seismic coverage of Australia (Figure 3a). This criterion alone reduces the exploration corridor in Australia to less than onequarter of the continent (Figure 3c). We tested the significance of the relationship using the two-sample Kolmogorov-Smirnov test, which estimates that the probability of global sediment-hosted deposits representing random continental locations is less than 1 in $10^{12}$ (Kolmogorov, 1933). Surprisingly, deposit types associated with magmatism do not follow this simple trend. Volcanogenic 

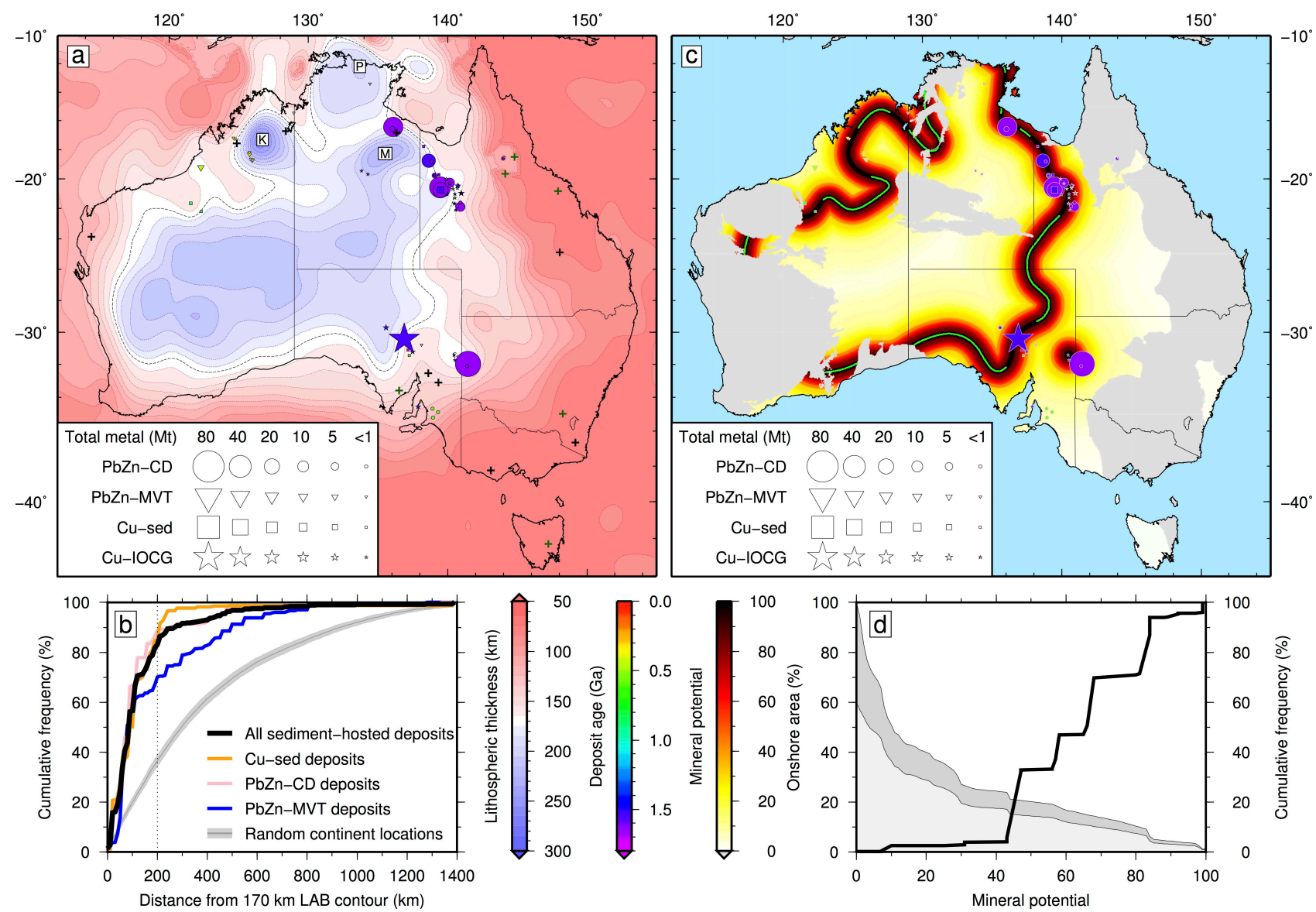

Figure 3 Distribution of sediment-hosted and IOCG deposits as a function of lithospheric thickness. (a) Australian LAB based on FR12 converted to temperature using an anelasticity parameterisation calibrated on local paleogeotherms; black dashed contour = $170 \mathrm{~km} L A B$ depth; symbols = deposit locations as in Figure 2, stars = IOCG deposits (largest is the Olympic Dam deposit); black/green crosses = geotherms used as constraints/tests in anelasticity calibration. Newly identified thick lithosphere blocks within northern Australia are named (K)imberley, $(P) i n e ~ C r e e k$ and $(M)$ urphy blocks. (b) Cumulative distribution function (CDF) for global sediment-hosted base metals, mass-weighted for 109 PbZn-CD, 147 PbZn-MVT and 139 Cu-sed deposits, and combination of all three; grey line/bound = mean and standard deviation of 100 sets of equivalent number of randomly drawn continental locations with respect to global $L A B$ enhanced over Australia. (c) Mineral potential heat map based on CDF distance with respect to $170 \mathrm{~km} L A B$ contour (a) in areas where stacked geological provinces contain lithological proxies for all four sediment-hosted mineral system components illustrated in Figure 1; green line = underexplored or unexplored portions of the $170 \mathrm{~km}$ contour more than $100 \mathrm{~km}$ away from known deposits where prospective rocks lie mostly undercover; symbols = deposit locations as in Figure 3. (d) Performance of the mineral potential heat map; solid line =CDF for Australian sediment-hosted base metals, mass weighted; dark grey = percentage of Australian area with $\geq$ mineral potential value based on distance to $L A B$ contour; light grey $=$ as before but for the clipped coloured region shown in (c).

massive sulfide and porphyry copper deposits are randomly distributed with respect to the $L A B$ edge, while magmatic nickel deposits are concentrated in regions of thicker lithosphere (see supplementary material of Hoggard et al., in press).

\section{Mineral systems implications}

This discovery has two important implications. First, the clustering of sediment-hosted base metal deposits on the edge of present-day thick lithosphere, regardless of their age, implies long-term lithospheric stability, spanning at least the last 2 billion years. Major pre- to syn-Paleozoic faults and shear zones of the North Australian Craton wrap around blocks of thick lithosphere, indicating that they have influenced strain partitioning and ore forming processes through multiple tectonic cycles (Figure 3a; Stewart et al., 2020). Other Australian observations that correlate with $L A B$ steps include variations in lead isotopes from Proterozoic galena and pyrite minerals, long-wavelength gravity anomaly gradients, topographic variations, the western extent of Phanerozoic sedimentary basins, and the pattern of surface drainage (Huston et al., 2020; Sandiford et al., 2020). These observations corroborate the longevity of cratonic roots.
Second, this relationship forces a reconsideration of sediment-hosted base metal mineral system models, which to date have not considered the mantle as a first-order control. Hoggard et al. (in press) highlight four important and interlinked factors (Figure 1). (1) Lithospheric thickness steps localise strain during rifting, focusing the optimal juxtaposition of mineral system components. Evaporites and oxidising terrestrial environments are located inboard, whereas restricted marine settings with reduced facies and volcanics derived from shallow decompression melting occur outboard. (2) Rifting of thick lithosphere results in a broader spatial and temporal window for mineralisation. Increased seismogenic thickness results in deeper, longer, more widely spaced normal faults, and a greater lateral extent of sediments deposited within grabens. These faults are also active for longer periods. The entire syn-rift phase of basin formation, generally associated with mineralisation, can last 50$100 \mathrm{Myr}$, in contrast to standard continental rifts that typically last <25 Myr. (3) Crucially, rifting of cratonic lithosphere results in deeper basins with lower geothermal gradients. Given that thermodynamic considerations limit metal precipitation conditions to less than $\sim 200^{\circ} \mathrm{C}$, these two features together substantially increase the depth extent of the mineral system operating window compared with 
standard lithosphere. (4) Deformation and exhumation along the edges of thick lithosphere are often mild, with orogenies generally focused in regions of thinner lithosphere. This setting therefore allows exhumation of deposits to the near surface, while increasing preservation potential through subsequent tectonic cycles. Notably, all of these factors contribute to cratonic edges being favourable for formation of giant deposits, but they do not preclude the generation of smaller deposits in standard lithosphere, thereby providing an explanation for minor outliers.

\section{Estimating mineral potential}

New predictive power from the LAB relationship can be combined with screening of stacked geological provinces for necessary lithologies. This approach provides a new perspective on the sediment-hosted base metal potential of Australia, reducing the exploration search space to just $\sim 15 \%$ of the continent with plenty of opportunities (Figure $3 d$ ).

This result highlights frontier exploration areas and allows estimation of undiscovered sediment-hosted base metal resources. Unexplored or underexplored regions along the prospective $170 \mathrm{~km} \mathrm{LAB}$ contour can be mapped by first projecting known deposits located within $200 \mathrm{~km}$ onto the contour, and then excising a $100 \mathrm{~km}$ radius around them (making the crude assumption that these regions have been explored). The remaining $\sim 3700 \mathrm{~km}$ of the contour provides an indication of the frontier search space in Australia, the majority of which lies undercover (Figure 3c). Globally, 26\% of the contour hosts known deposits, yielding an estimated average endowment of $\sim 55 \mathrm{kt}$ of base metals per kilometre of contour. Applying these values to the length of underexplored contour in Australia suggests that $~ 50-200 \mathrm{Mt}$ of base metals (worth $\sim \$ 1$ trillion) are still to be discovered in Australian frontier basins. These estimates are equivalent to the known resource in the North Australian Zinc Belt $(\sim 130 \mathrm{Mt}$ $\mathrm{Pb}+\mathrm{Zn}+\mathrm{Cu}$ ) and the Olympic Dam IOCG deposit (>80 Mt Cu).

\section{Conclusion}

The discovery that $85 \%$ of sediment-hosted base metals, including all the world's giant deposits, are found within $200 \mathrm{~km}$ of the edge of thick lithosphere has (1) forced revision of mineral systems and basin dynamic models within the context of lithospheric stability; (2) provided the first statistical basis for translating mineral system models to mappable proxies on global scales, and a new means of identifying frontier fertile basins; and (3) indicated, in combination with geological proxies, that $\sim 50-200 \mathrm{Mt}$ of base metals and associated critical minerals are likely to be still discovered in Australia. Taken together, these considerations suggest that the discovery of a new world-class sedimenthosted base metal minerals province in undercover Australia is realistic, and enable refocusing of exploration to achieve it.

\section{Datasets}

$\mathrm{LAB}$ grids can be downloaded from:

http://pid.geoscience.gov.au/dataset/ga/132624.

\section{Acknowledgements}

O. Raymond, C. McKenna and C. Brown assisted in developing ASUD queries. This abstract was improved by reviews from $R$. Blewett and $J$. Thorne. This abstract is published with the permission of the CEO of Geoscience Australia.

(C) Commonwealth of Australia (Geoscience Australia) 2020 eCat: 134991, doi: 10.11636/134991

\section{References}

Ali S. H., et al., 2017. Mineral supply for sustainable development requires resource governance. Nature 543:367-72.

Fishwick S. \& Rawlinson N., 2012. 3-D structure of the Australian lithosphere from evolving seismic datasets. Australian Journal of Earth Sciences 59:809-26.

Gorbatov A., et al., 2020. AusArray: towards updatable, national high-resolution seismic velocity models of the lithosphere. In Czarnota K., et al. (eds.) Exploring for the Future: extended abstracts, Geoscience Australia, Canberra, 1-4.

Griffin W. L., Begg G. C. \& O'Reilly S. Y., 2013. Continental-root control on the genesis of magmatic ore deposits. Nature Geoscience 6:905-10.

Hitzman M. W., Selley D. \& Bull S., 2010. Formation of sedimentary rock-hosted stratiform copper deposits through Earth history. Economic Geology 105:627-39.

Hoggard M. J., et al., in press. Global distribution of sedimenthosted metals controlled by craton edge stability. Nature Geoscience 13.

Hronsky J. M. \& Groves D. I., 2008. Science of targeting: definition, strategies, targeting and performance measurement. Australian Journal of Earth Sciences 55:3-12.

Huston D., et al., 2020. Crustal-scale controls on zinc-lead-silver deposits of the North Australian Zinc Belt: evidence from isotopic and geophysical data. In: Czarnota K., et al. (eds.) Exploring for the Future: extended abstracts, Geoscience Australia, Canberra, 1-6.

Kolmogorov, A. N., 1933. Sulla determinazione empirica di una legge di distribuzione. Giornale dell'Istituto Italiano degli Attuari 4:83-91.

Leach D. L., et al., 2010. Sediment-hosted lead-zinc deposits in Earth history. Economic Geology 105:593-625.

Manning A. H. \& Emsbo P., 2018. Testing the potential role of brine reflux in the formation of sedimentary exhalative (sedex) ore deposits. Ore Geology Reviews 102:862-74.

McKenzie D. P., 1978. Some remarks on the development of sedimentary basins. Earth and Planetary Science Letters 40:25-32.

Mudd G. M., et al., 2018. Critical minerals in Australia: a review of opportunities and research needs, Record 2018/51, Geoscience Australia, Canberra.

Priestley K. \& McKenzie D., 2013. The relationship between shear wave velocity, temperature, attenuation and viscosity in the shallow part of the mantle. Earth and Planetary Science Letters 381:78-91.

Richards F. D., Hoggard M. J., Cowton L. R. \& White N. J., 2018. Reassessing the thermal structure of oceanic lithosphere with revised global inventories of basement depths and heat flow measurements. Journal of Geophysical Research: Solid Earth 123:9136-61.

Richards F. D., Hoggard M. J., White N. J. \& Ghelichkhan S., in press. Exploring the relationship between upper mantle structure and short wavelength dynamic topography using calibrated anelasticity parameterizations. Journal of Geophysical Research.

Sandiford M., Lawrie K. \& Brodie R. S., 2020. Hydrogeological implications of active tectonics in the Great Artesian Basin, Australia. Hydrogeology Journal 28:57-73.

Schaeffer A. J. \& Lebedev S., 2013. Global shear speed structure of the upper mantle and transition zone. Geophysical Journal International 194:417-49.

Schodde R., 2017. Long term trends in global exploration: are we finding enough metal? In: $11^{\text {th }}$ Fennoscandian Exploration and Mining Conference, 31 October 2017, Levi, Finland.

Stewart A. J., Raymond O. L., Totterdell J. M., Zhang W. \& Gallagher R., 2013. Australian Geological Provinces WFS, revised 2018 [digital dataset], Geoscience Australia, Canberra.

Stewart A., et al., 2020. Seamless chronostratigraphic solid geology of the North Australian Craton. In: Czarnota K. et al. (eds.) Exploring for the Future: extended abstracts, Geoscience Australia, Canberra, 1-6.

Yamauchi H. \& Takei Y., 2016. Polycrystal anelasticity at nearsolidus temperatures. Journal of Geophysical Research: Solid Earth 121:7790-820. 